\title{
Assessing the Impact of Fire Safety Training at a University's Information and Communication Technology Unit
}

\author{
Louisa Sheeta Arthur, Timothy Simpson*, Kojo Ennin Oppan \\ Faculty of Applied Sciences, Technical University. P. O. Box 256, Takoradi, Ghana
}

\begin{abstract}
Over the years, the educational institutions have had fair share of unfortunate fire incidents. Although incidents of fire are rare and occasional, the chaotic and unplanned nature of responses when fire incidents occur show the extent of preparation staff and students have in dealing with these crises situations. In a computing environment within a university, even though the likelihood occurrence of fire originating from equipment such computers, cables and network devices is unpredictable, the impact on operations of a tertiary institution is greatly affected. When it occurs, it leads to loss of critical application systems which support teaching, learning and administration, damage to expensive equipment, loss of stored records and finally leading to life threatening consequences to occupants. The study employed quantitative method to evaluating impact of fire safety training. Data was obtained using survey questionnaire to gather responses from those who attended in the event hosted by Takoradi Technical University's Directorate of Information and Communication Technology(ICT) Services. Descriptive statistics was used in data analysis to give meaning to figures. Results revealed that the training program built the capacity of participants to respond to fire safety issues appropriately and knowledgeably. Based on the findings it was recommended fire safety training be organized frequently for members of the university community for them to be able respond appropriately to crises situations should it occur.
\end{abstract}

Keywords: Fire, university, incident, safety

DOI: $10.7176 / \mathrm{IKM} / 9-4-07$

Publication date: April $30^{\text {th }} 2019$

\section{Introduction}

Fire incidents are often not given the focused attention it deserves because its occurrence is unexpected and spontaneous; however its impact is most often costly and come with devastating consequences. Fire incidents are recorded frequently with the major impacts gaining headlines in the traditional news media. Fire is an element which has been described both a servant and master in circumstances when it is fit for purpose or otherwise when it in its destructive form. In other words, one must be careful to use fire in a wise manner and under control so that it does not hurt anyone (McGraw-Hill Dictionary of American Idioms and Phrases, 2002). Rightfully so, there are numerous benefits on the use of fire in our daily domestic lives such as cooking, heating and accelerating processes. At workplaces where heat or combustion is fire is required, it is used to perform tasks such as welding, smelting and heating. The rate of fire outbreaks can be reduced by adhering to safety practices.

Takoradi Technical University is a tertiary institution situated in Takoradi in the Western region of Ghana. It was transformed from a polytechnic to its current status following an act of Parliament in 2016. The university receives patronage from prospective student applicants living in and around the Western Region of Ghana. Established as servicing Unit in 2012, the University's ICT Directorate is responsible for the Information, Communication and Technological needs of the University. Its vision is to equip the University with the stateof-the-art technological infrastructure that would grant the University the competitive advantage to enhance teaching, learning, research and administrative prowess (Takoradi Technical University Website, 2018).

The Directorate has additional responsibility to establish a comprehensive Incidence Response, Business Continuity and Disaster recovery procedures for all ICT resources. (ICT Services and Systems; Management, Control Maintenance and User Policy, 2016). Recommendations by Audit Committee of the University also revealed the need for the ICT Directorate to put in place adequate measures to improve workplace safety. In line with this, and other recommendations, the Directorate hosted a training programme to educate and train staff members on Fire Safety. In attendance were a cross-section staff and students of the university.

This study was conducted to investigate the extent of preparedness the University community, most especially persons at the Directorate of ICT Services, in the event of a fire disaster and how to respond to the occurrences of same based on the impact of training programme held. 


\section{Theoretical perspectives}

Fire incidents do occur accidentally and sometimes negligently due to lack of adherence to safety practices (Aggrey-Korsah, 2018). Fire incidents are recorded by the Ghana National Fire service and are classified into causes categories namely, Domestic, Industrial, Commercial, Electrical and Bush Fires (GNA, 2019). Statistics over the years have revealed greater percentage of fire incidents being Domestic and Bush fires with least being domestic fires (Addai et al., 2016). The rate of fire outbreaks in recent times is of concern to the citizenry. This is because its impact to lives and property is usually devastating.

\subsubsection{Causes of fire incidents}

The causes of fire according to the GNFS public relations officer and reported by Nutifafa (2018) include improper and careless use of Liquefied Petroleum Gas (LPG), non-maintenance of electrical equipment and installations, unattended cooking devices, overheating of circuit, improper storage an handling of flammable liquids, overloading of electrical sockets, upsurge and power fluctuations, improper disposal of cigarette, careless usage and handling of naked fire, deteriorated electrical lines. Addai et al. (2016) in their analysis of pattern of fire in incidents in Ghana from 2000 to 2013 revealed a yearly increase in trend. The study attributed this phenomenon to increase in human population and proportional increase in human activities involving the use of fire. Injuries, loss of lives and properties were associated with these incidents. Domestic fire accounted for most frequent cause of fire incidents, being $41 \%$ of total number while industrial fire recorded the least. Twum Barima (2014), in assessing the awareness of fire incidents in the informal sector attributed the major cause of fire incidents to electrical related problems. He further broke it down the causes as power fluctuations, overloading of electrical appliances, outdated electrical wiring system, illegal tapping of electrical power from main power source, faulty generators, and substandard electrical materials.

Anaglate (2016) and corroborated Addai et al. (2016) indicate that the cause of fire outbreaks are preventable since these incidences occur as a result of lack of fire safety training, awareness and negligence on the part of the citizenry. They point out that basic safety rule when adhered to, could have helped avoid many of fire outbreaks.

\subsubsection{Chemistry of fire}

Fire is described as the visible effect that occurs during the process of combustion. The word 'Fire' is often used interchangeably with the word 'combustion'. Addai et al.(2016) defined Fire as a raid, self-sustaining oxidation process, accompanied evolution of heat and light at unstable intensities. Comparable definition in Webster's New World College Dictionary defined fire as a rapid, persistent chemical change that releases heat and light and is accompanied by flame, especially the exothermic oxidation of a combustible substance (Duckett, 2005). Previous studies state that fire occurs when three components are heat, oxygen, and fuel. Recent studies state a fourth element being chemical chain reaction that occurs. The four is described in a diagram referred to as Fire Tetrahedron. Taking one or more element of fire tetrahedron can extinguish a fire.(Firesafe.org, 2019) The risk of fire incidents cannot be underestimated. Fire begins by a source of ignition in the form of a flame, or spark. It heats a fuel combustible material) in the presence of oxygen. The combustible material or fuel heats at elevated intensity, thereby creating a self-sustaining chemical chain reaction, which becomes visible as smoke or warm light (Aggrey-Korsah, 2018).

There are a least fire classifications found in literature: Class A, Class B, Class C, Class D, 'Electrical', and Class F. Class A fires refers to combustible materials caused by flammable solids, such as wood, paper, and fabric Class B fires refer to fires caused by flammable liquids such as petrol, turpentine or paint. Class $\mathrm{C}$ fires refer to fires caused by flammable gases like hydrogen, butane or methane. Class D fires refer to fires caused by combustible metals: chemicals such as magnesium, aluminum or potassium. Electrical fires refer to fires caused by electrical equipment: once the electrical item is removed because its classification appears unclear. Class $\mathrm{F}$ fires refers to fires caused by cooking oils: typically a chip-pan fire (OSHA, 2018; Fire Safety Advice Centre, 2017).

\subsubsection{Ghana National Fire Service and operations in the Western Region}

The national constitution, specifically article 190, of 1992 refers to the institutionalization of Ghana National Fire Service (GNFS). The GNFS ACT 537 was accented to and gazetted in 1997. The objective of the GNFS put in measures to ensure safety with regards to fire incidents anywhere in the country. Their function is to organize 
public fire education programs by creating and sustaining awareness of hazards of fire as well as heighten the role of individuals in the prevention of fire. They are also to provide technical advice and undertake fire rescue operations (GNFS Act, 1997) The Service recorded of 4,544 cases of fire outbreaks country in 2017 (GNA, 2019). The Western region of Ghana recorded a total of 415 in that same year. An incident that gained headlines in the news during the year was that of a gas explosion which occurred in a suburb in Takoradi, few metres away from Takoradi Technical University in May 2017 (Myjoyonline.com, 2017). Reports indicated that fire safety officers and others numbering about 50 were injured.

The service has responded generally to their core mandate in times of distress. However, challenges such as improper/unplanned settlement layout among others tend to hamper fire-fighting effort of Fire service personnel. Figure 1 shows a pattern of fire incidents from 2017 to the second quarter of 2018 in the Western Region.

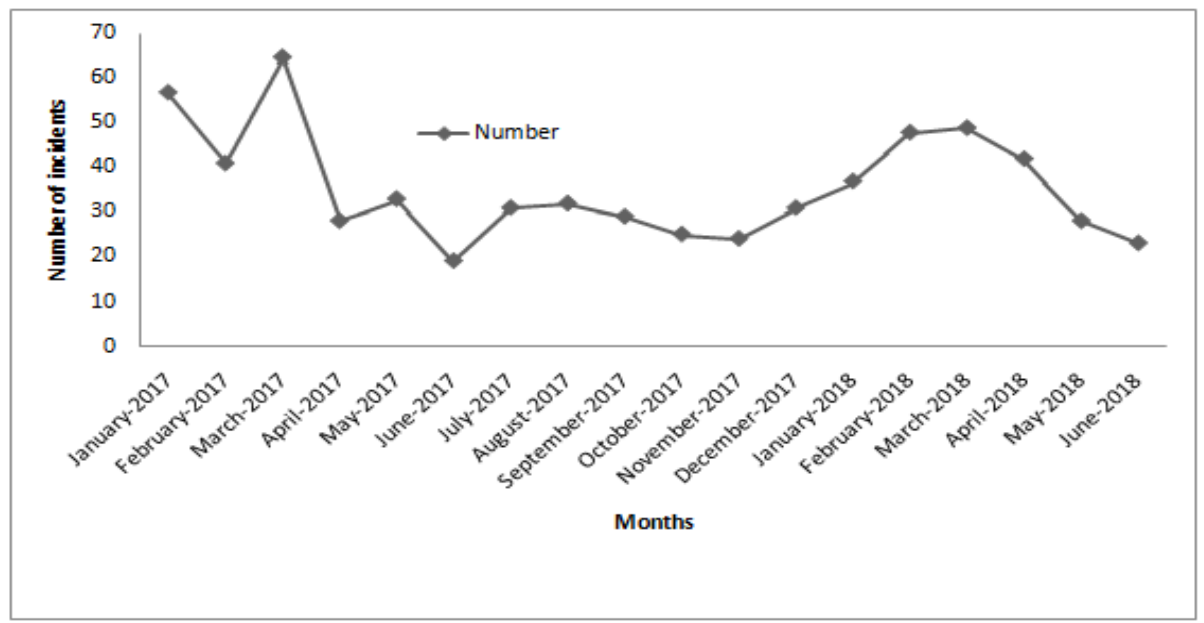

Fig. 1. Pattern of fire incidents (1st,2nd, 3rd, 4th quarter 2017 and 1st \& 2nd quarter 2018 ) in the Western Region. (Data Source: Western Regional Command, Ghana National Fire Service)

At the workplace, destruction caused fire may result in damage to machinery, production material, lives and personal property. The Labour Act (2003) implores employers and employees to put in place measures to ensure safety at all times at workplace. It is the responsibility of an employer to provide instruction, training and supervision of workers to ensure health and safety at workplace including but not limited to fire safety Employer are to provide workers with adequate safety appliances, suitable for fire-fighting equipment, personal protection equipment, instruct workers in the use of such appliances or equipment. In return, workers are under obligation to use the safety s appliances, suitable for fire-fighting equipment, personal protection equipment provided by the employer in compliance with employer's instructions (Labour Act, 2003).

\subsubsection{Recommendation solution to fire incidents}

Addai et al. (2016) recommend public education on fire safety, enforcement of fire safety regulations, redevelopment of informal settlements, formation of community fire volunteers and provision of fire hydrants at strategic locations. Moreover, they recommend rehabilitation and use of standard electrical wiring systems.

Fanfarova and Maris (2017) recommend the use of simulation technologies to trains individuals on fire safety. They argue that training in live emergency situations such as extinguishing of vehicle fire, explosions, and evacuating people in fire situation is costly, dangerous and extremely impossible. The advocate the use of simulators, similar to those used by pilots, that can set various to crises situation to train personnel in fire fighting.

\subsection{Objective of this study}

The main focus of this study is to assess the impact of fire safety training and preparedness of workplace occupants in the event of a fire disaster in tertiary institution in Ghana, specifically Takoradi Technical University. The focus was on the ICT Unit of the University. The study seeks answers to the following questions. 
i) How ready and prepared are members to face the risk of fire disaster?

ii) Are members sensitized on appropriate fire safety measures and practices?

iii) How knowledgeable are members to respond appropriately to fire incidence should it occur?

iv) Are members trained adequately on appropriate on actions take in the event of a fire incident?

\section{Method and Materials}

\subsection{Materials}

Materials used at the training session include sand five (5) fire extinguishers, blanket, water, aluminium head pan and petrol.

\subsection{Data sources}

Both primary and secondary sources of data were used. The primary data include, questionnaire, interviews and observations. Secondary sources include scholarly research journals, GNFS released statistical reports on fire incidents and news media publications.

\subsection{Population}

The population was cross-section of the University Community who participated at a Fire Safety training event hosted by the Directorate of Services. Questionnaires were distributed to 50 participants. Purposive sampling technique was used in selecting respondents. The rate of return was $76 \%$, out of which $70 \%$ were filled completely. The questions were divided into categories. The first category of questionnaire focused on identification of data respondents (age, gender, and status and rest of categories bother on views of respondents with respect impact of the training programe. The gained results were statistically evaluated and analyzed.

\subsection{Procedure}

A 4-hour training session was organised in two parts: a 2-hour theoretical session and 2-hour practical session.

Classroom Session

The resource person took participants through lessons with respect to fire safety. Lessons they were taken through include: the chemistry of combustion, fire hazards, detection and prevention, protocol involved in extinguishing fire and the role of the Ghana National.

Different substance-based fire extinguisher types: water, foam, dry powder, CO2 and wet chemical which are capable of suppressing different causes of fire were explained. The safety officer also shared experiences in fire combat and rescue operations he has been involved in. He also shared some challenges that he and his team encounter during the course of their work. This includes difficulty in accessing areas to combat fire and. disregard for basic fire safety by measures by some members of the general public. Participants were given the chance to ask questions with regarding the presentation. Responses were accordingly provided.

\section{Practical Session}

Participants were taken to an open-space assembly point for a pre-practical session briefing. A barricade tape (caution tape) was used to surround an area measuring about 50 meters square. This is to identify the area dedicated for the demonstration a hazard zone. The head pad was half-filled with sand and placed in the middle of the open space. About a litre of petrol was poured in the container. The mixture was lit resulting in a flame of fire. The resource person called out volunteer to employ tactics below to extinguish the fired created.

\section{Activity}

i) Use of water. Water was sprinkled on the flame in an attempt to put it out.

ii) Use of damp blanket. : Blanket soaked with water was used cover the flame.

iii) Use of fire extinguisher: Different types of fire extinguisher were used in an attempt to cover was used to quench the fire created with the petrol. A drill pattern remembered with acronym P. A. S. S. was practiced on illustrates effective use of fire extinguisher:

$\mathrm{P}$ - Pull the safety pin or locking mechanism from the handle.

A - Aim the extinguisher nozzle or hose at the base of the fire.

$\mathrm{S}$ - Squeeze the handle or lever slowly to discharge the agent.

$\mathrm{S}$ - Sweep side to side approximately 6 in or $15 \mathrm{~cm}$ over the fire until expended. The fire was restarted for other 
volunteers to have their turn.

\section{Result of activity}

Activity (i) rather increased the intensity of the fire. Purpose was to explain that, water is not ideal for all type of fire. Hence, fires must be fought carefully depending on the materials involved.

Activity (ii) was able to quench the fire. The explanation was that the flame was starved air. The lesson learnt was to illustrate that the removal of any one of three fire formation element (oxygen/air, fuel, heat) can causes fire to extinguish.

Activity (iii) did extinguish the fire. Purpose was to illustrate that that prior training on correct use is indeed a necessity and can alleviate fear and indecision in the event of combating fire incident.

\section{Result and Discussion}

This section makes a presentation of the analysis obtained from the responses given by the respondents. The analysis results were obtained by means of SPSS and the presentation was done in the form of tables and charts with each table and charts followed by the description of it content.

\subsection{Respondents by percentage.}

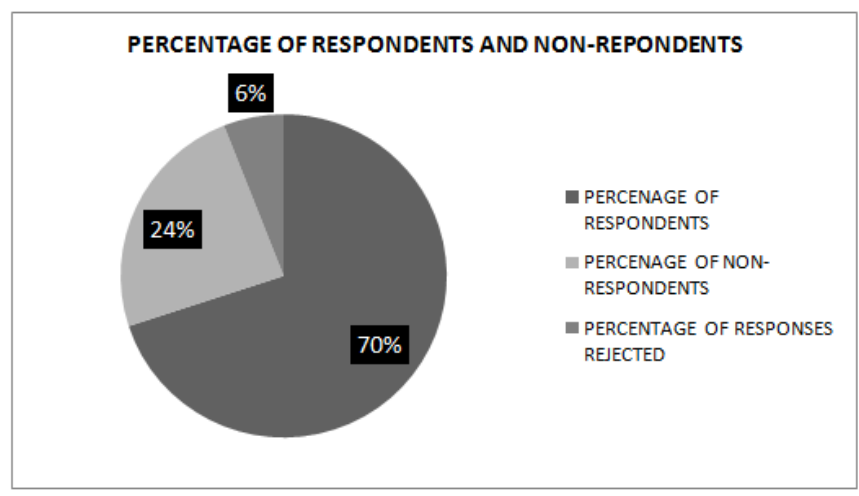

(Source: Field work 2018)

Fig. 6. Respondents by percentage

The above figure clearly shows the response percentage, from figure 6 it is seen that percentage of respondents is 70 which constitute the Majority whiles 30 percent constitute percentage of non-respondents.

\subsection{Event outcome}

The primary purpose of this section is to evaluate the overall goals of the training as a whole

\section{Table 1: The Overall Goals of the Training}

\begin{tabular}{lllll}
\hline Statement & Agree $\%$ & Neutral\% & Disagree $\%$ & Mean \\
\hline $\begin{array}{l}\text { The training has enhanced my knowledge in } \\
\text { how to identify and reduce the risk that fire } \\
\text { present in workplace }\end{array}$ & 100 & 0 & 0 & 1.00 \\
$\begin{array}{l}\text { The training has enhanced my understanding } \\
\text { about fire safety and awareness about what } \\
\text { should be done in the event of fire incidence }\end{array}$ & 100 & 0 & 0 & 1.00 \\
$\begin{array}{l}\text { The training helped build my capacity to } \\
\text { respond appropriately to the fire incidence }\end{array}$ & 100 & 0 & 0 & 1.00 \\
\hline Overall & & & 1.00 \\
\hline
\end{tabular}

(Source: Field Work, 2018)

Table 1 shows the overall goals of the training as a whole, considering the statement 'The training has enhance my knowledge in how to identify and reduce the risk that fire present in workplace' all the respondents agreed to 
the statement with a mean response of 1.00 corresponding 100 percent. Moreover, all the respondents constituting 100 percent with a corresponding mean of 1.00 agreed that the training has enhance their understanding about fire safety and awareness about what should be done in the event of fire incidence. Lastly, 100 percent of the respondents with a mean response of 1.00 agreed that the training has helped them build their capacity to respond appropriately to the fire incidence.

4.3 Meeting and training structure

The prime purpose of this section is to access the satisfaction of the meeting logistics.

Table 2: Satisfaction with (Training /Structure) Logistics

\begin{tabular}{lllll}
\hline Statement & Satisfied $\%$ & Neutral $\%$ & Dissatisfied $\%$ & Mean \\
\hline The meeting venue & 100 & 0 & 0 & 1.00 \\
$\begin{array}{l}\text { Refreshment } \\
\begin{array}{l}\text { Practical session location/Training } \\
\text { materials }\end{array}\end{array}$ & 66.7 & 9.5 & 23.8 & 1.23 \\
\hline Overall & 100 & 0 & 0 & 1.00 \\
\hline
\end{tabular}

(Source: Field work, 2018)

As depicted in table 2, all the respondents constituting 100 percent with a mean response of 1.00 were well satisfied with the meeting venue. Moreover, majority of the respondents recording 66.7 percent surveyed retorted that they were well satisfied with food prepared for them with a corresponding mean of 1.23 whiles minority of the respondents surveyed responded that they were dissatisfied with food prepared for them constituting 23.8 percent. Lastly, all the respondents were satisfied with the practical session location with a mean response of 1.00 .

Table 3: Structural Component of the Training Structure

\begin{tabular}{lllll}
\hline Statement & Satisfied\% & Neutral\% & Dissatisfied\% & Mean \\
\hline Facility & 100 & 0 & 0 & 1.00 \\
Time for questions & 95.1 & 4.8 & 0 & 1.05 \\
Schedule & 95.2 & 4.8 & 0 & 1.05 \\
Skills training sessions & 100 & 0 & 0 & 1.00 \\
Presentation & 100 & 0 & 0 & 1.00 \\
\hline Overall & & & 1.02 \\
\hline
\end{tabular}

(Source: Field work 2018)

Table 3 depict the structural component of the Training structure, all the respondents surveyed retorted that they were satisfied the facility, hence constituting a mean response of 1.00. Again, a greater proportion of the respondents constituting 95.1 percent answered that they were satisfied with the time for questions with a mean response of 1.05. In addition, majority of the respondents indicated that they were well satisfied with time Schedule (timing of sessions) constituting 95.2 percent. Moreover, all the respondents noted that they well satisfied with the skills training sessions, thus corresponding 100 percent. Lastly, all the respondents are well satisfied with the presentation constituting 100 percent with a corresponding mean response of 1.00.

\subsection{Resource person's delivery}

The prime purpose of this section is to evaluate the overall performance of facilitator 
Table 4.: Overall Performance of the Facilitator

\begin{tabular}{lllll}
\hline Statement & Excellent\% & Good\% & Fair\% & Mean \\
\hline $\begin{array}{l}\text { Resource person was well prepared } \\
\begin{array}{l}\text { Resource person presented information in } \\
\text { terms i understood }\end{array}\end{array}$ & 81 & 19 & 0 & 1.19 \\
$\begin{array}{l}\text { Resource person was knowledgeable in } \\
\text { topics instructed }\end{array}$ & 81 & 47.6 & 0 & 1.48 \\
$\begin{array}{l}\text { Resource managed well in meeting } \\
\text { workshop objectives }\end{array}$ & 52.4 & 19 & 0 & 1.19 \\
$\begin{array}{l}\text { Resource person shared relevant } \\
\text { experience and insights }\end{array}$ & 42.9 & 47.6 & 0 & 1.48 \\
$\begin{array}{l}\text { Resource person responded well to } \\
\text { questions }\end{array}$ & 76.2 & 57.1 & 0 & 1.57 \\
$\begin{array}{l}\text { Resource persons responded well to } \\
\text { suggestions }\end{array}$ & 57.1 & 23.8 & 0 & 1.24 \\
$\begin{array}{l}\text { Resource person integrated participations } \\
\text { comments well }\end{array}$ & 42.6 & 42.9 & 0 & 1.43 \\
$\begin{array}{l}\text { Resource person should continue to } \\
\text { facilitate }\end{array}$ & 61.9 & 52.4 & 0 & 1.52 \\
\hline $\begin{array}{l}\text { Overall } \\
\text { Source: Fin wor }\end{array}$ & 38.1 & 0 & 1.38 \\
\hline
\end{tabular}

(Source: Field work 2018)

As shown in table 4, majority of the respondents answered that the resource person preparation was excellent constituting 81 percent with a corresponding mean of 1.19. Main stream of the respondents retorted the resource person excellently presented information to their understanding recording 52.4 percent. Again, 81 percent of the respondent replied that the resource person has an excellent knowledge in the topic instructed. A greater proportion of the respondents constituting 52.4 percent responded that resource person excellently managed to meet workshop objectives. In addition, 57.1 percent of the respondents alleged that the facilitator was good in sharing relevant experience and insights. 76.2 percent of the majority of the respondents answered that the resource person responded excellent to questions. The mean response was 1.24. Moreover, most of the respondents said the resource persons also responded excellent to their suggestions. Furthermore, 52.4 percent of the respondents responded that the resource person did well in integrating feedback commentaries into the training. Lastly, 61.9 percent of the people surveyed recommended that the resource person should continue to facilitate this training program

3.5 Overall level of satisfaction with the fire safety Training

The Major purpose of this section seeks to rate the overall satisfaction with the fire safety training.

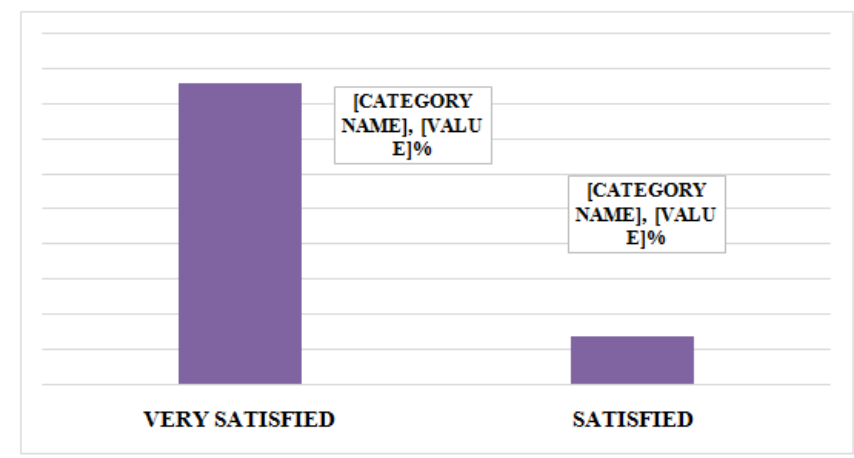

(Source: Field work 2018)

Fig 9. Overall level of satisfaction with the fire safety training. 
Majority of the respondents are very satisfied with the fire safety training constituting 86 percent whiles, 14 percent of the respondents are satisfied with the fire safety training.

Respondents suggested the slides, different kind of training videos should be provided. Again some of the participants suggested that the training program should be organized on monthly basis. Moreover, most of the respondents suggested that the training must be a must to all the institution and also institution needs to have fire extinguisher to safe guard their environment. Lastly, a proportion of the respondents responded that the practical section of the training should include combustible material and fats to enhance their practical orientation.

\section{Conclusion}

From the discussion so far, it can be observed that the training program enhance the knowledge of participants with respect to fire safety. From the study it can be concluded that in the event of fire incidence at a workplace, knowledge about fire hazards including prevention and how to react confidently and appropriately has the potential of escalating or bringing situation under control.

\section{Recommendation}

From the training programme, a number of recommendations were outlined by the safety officer for participants. First and foremost, the safety and the safety of fellow workers come first in the event of a fire outbreak. Moreover, following simple fire safety practices can prevent fires at workplace and reduce injuries and loses. Members of the university community should know the location of building exits, location of nearest fire alarms, fire extinguishers and how to use them. Fire should be put out at early stages only if you are confident that it can be put out.

Participants call on management to conduct regular fire safety training for all staff and include activation emergency fire drills regularly to assess the readiness of staff in emergency situations They called on management to provide employees with adequate fire-fighting equipment and personal protective equipment at workplace. Additionally, the resource person called on management to ensure that workplace buildings have adequate fire safety installations and emergency exits. The officer recommended the appointment and training of fire safety marshals who will be responsible in ensuring safe evacuation and coordinate ongoing safety programs

Overall, the feedback from training programme indicate improved preparedness members of the university for future crises and emergencies and positive potential appropriate response to handle the impact confidently, should it occur.

\section{References}

Anaglatey, P. B. (2017). Ghana National Fire Service Fire Service statistics report, Accra

Fanfarova, A. and Maris, L. (2017). Simulation Tool for fire and rescue services. International Scientific Conference on Sustainable, Modern and Safe Transport. Procedure Engineering 192(2017) 160-165

Addai, E.K, et al. (2016). Trend of fire outbreaks in Ghana and ways to prevent these incidents, Safety and Health at Work, SHAW-2016.02.004 pages 1-9

Aggrey-Korsah, J. (2018). Fire Safety Training- Theory and Practical presentation by Mr Jude Aggrey-Korsah, Assistant Division officer of Ghana National Fire Service(GNFS), Shama. Fire safety Education held at Takoradi Technical University Auditorium. July 312018.

Duckett B, (2005). Webster's New World College Dictionary (4th edition), Reference Reviews, Vol. 19 Issue: 8 , pp.35-36

Fire Safety Advice Centre (2018). Information about the Fire Triangle/Tetrahedron and Combustion. Fire Safety Advice Centre, U.K. Retrieved September 2, 2019 from https:/www.firesafe.org.uk/information-about-the-firetriangletetrahedron-and-combustion/

Fire Safety Advice Centre (2018) Classes of Fire Retrieved September 2, 2018, from https://www.firesafe.org.uk/portable-fire-extinguisher-general/

Ghana National Fire Service Act (1997) ACT-537. Ghana National Fire service Act. Retrieved December 12, 2018 from http://laws.ghanalegal.com/acts/id/148/ghana-national-fire-service-act

Ghana News Agency-GNA (2019) Western Region Records 328 Fire-Cases in 2018 http://www.ghananewsagency.org/social/western-region-records-328-fire-cases-in-2018-144481 
Hamidovic, H. (2014). Fire Protection of Computer Rooms- Legal Obligations and Best Practices. ISACA Journal Volume 4, 2014. Retrieved January 2, 2019 from https://www.isaca.org/Journal/archives/2014/Volume4/Pages/Fire-Protection-of-Computer-Rooms-Legal-Obligations-and-Best-Practices.aspx

ICT Services and Systems; Management, Control Maintenance and User Policy (2016). Takoradi Technical University

Labour Act (2003) ACT 651 Retrieved January 12, 2019, from http://laws.ghanalegal.com/acts/id/162/labour-act McGraw-Hill Dictionary of American Idioms and Phrases (2002). The McGraw-Hill Companies Inc.

Myjoyonline.com (2017). Gas explosion in Takoradi leaves fire officers, 50 others injured. Retrieved January 10 , 2018 from https://www.myjoyonline.com/news/2017/may-9th/gas-explosion-in-takoradi-leaves-fire-officers-50others-injured.php

Nutifafa, A. (2017). Fire Service records 1, 852 Fires incidences in 2017 Qtr 1. Retrieved February 10, 2019 from http://ghananewsonline.com.gh/fire-service-records-1-852-fires-incidences-2017-qtr-1/

OSHA (2018). Classification of Portable Fire Extinguishers-Occupational Safety and Health Administration, USA. Retrieved December 12, 2018 from http://www.osha.gov/doc/outreachtraining

Takoradi Technical University Website. (2018). Retrieved Feb 4, 2018 from http://www.ttu.edu .gh/

The Constitution of the Republic of Ghana. (1992). Retrieved February 10, 2019 from http://www.ghana.gov.gh/images/documents/constitution_ghana.pdf

Twum-Barima, I. M. (2014). An Assessment of the awareness of fire insurance in the informal sector; case study of Kumasi central market in Ghana. International Journal on Human and Social Science Education (IJHSSE) 2014; $1: 41-7$

\section{Acknowledgements}

The authors would like to express profound appreciation to all key personalities whose effort contributed towards successful organisation of the fire safety training programme. Acknowledgement goes to following:

Rev, Professor John Frank Eshun, Vice Chancellor, Takoradi Technical University

Mr Jude Aggrey-Korsah (ADO), Assistant Division Officer II, Ghana National Fire Service (GNFS) - Shama

District, Western Region

Mr Ernest Kodjordie, Webmaster, Takoradi Technical University

Lord Kweku Sekyi, Journalist

Edwin Nana Conduah, Photography

Staff of Directorate of ICT Services

Staff and students of Takoradi Technical University

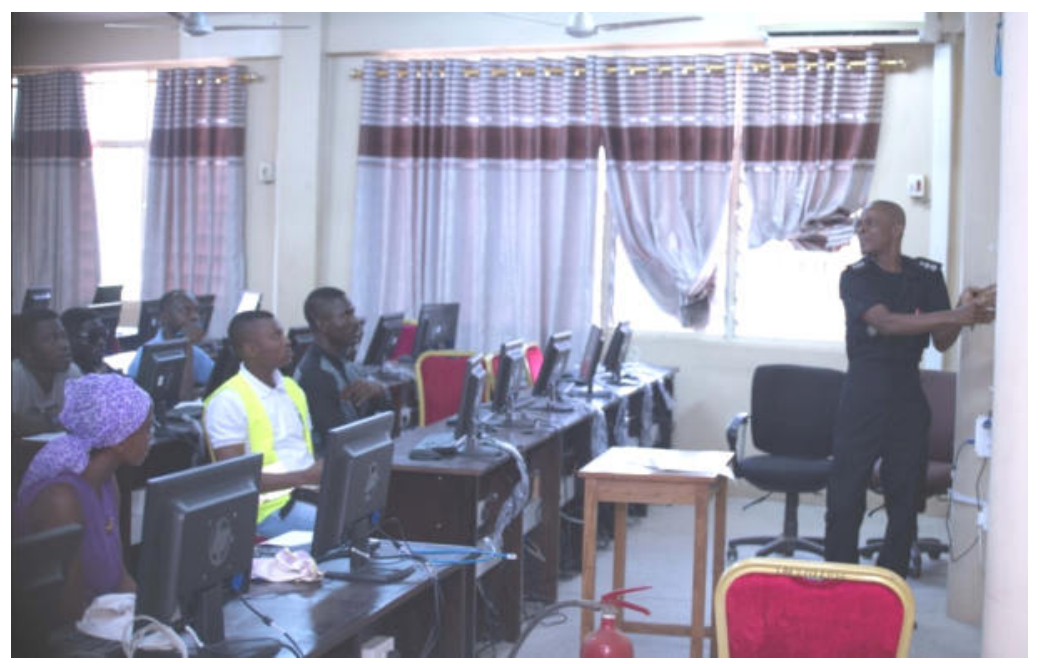

Fig. 2. Fire safety lesson at being held at Directorate of ICT Services Computer lab 


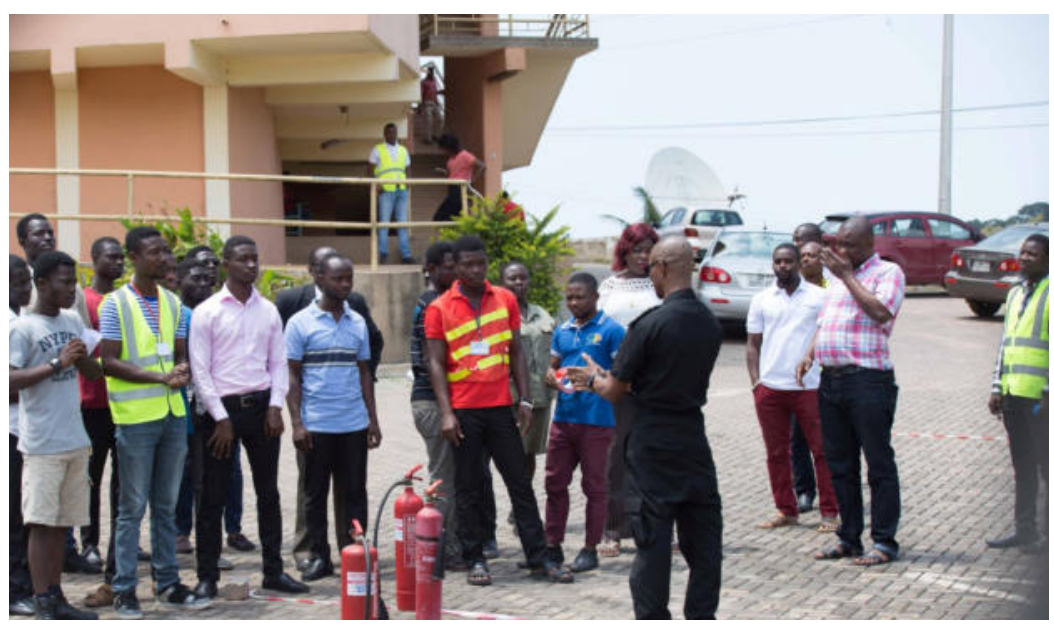

Fig 3. Pre-practical session briefing

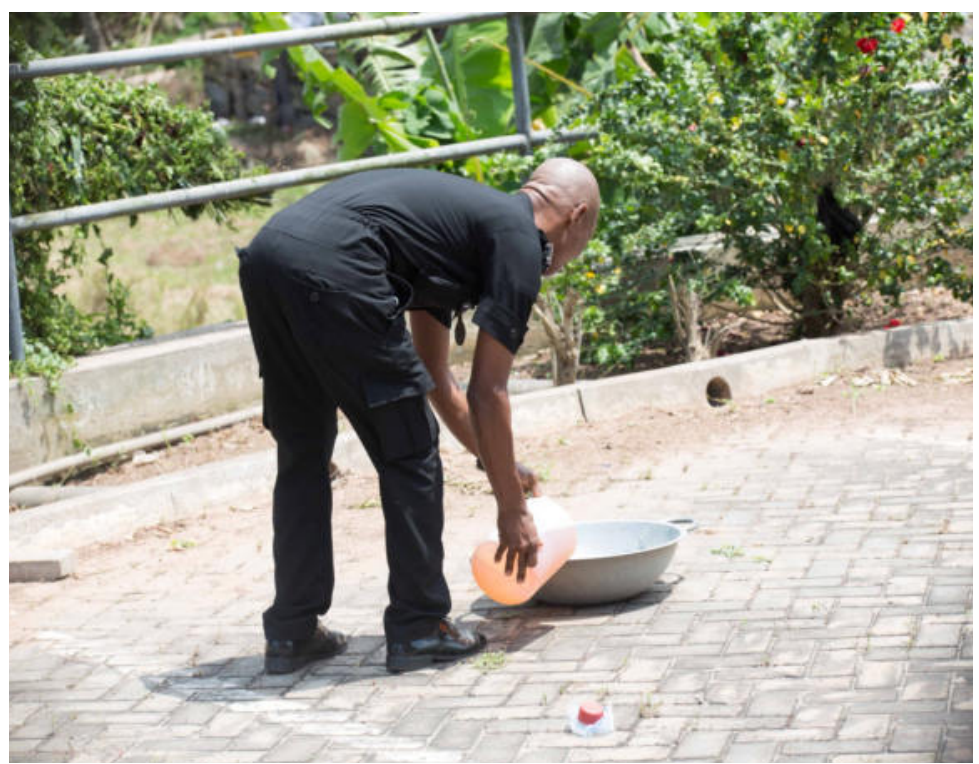

Fig. 4. Instructor pouring petrol into head pan half-filled with sand 
$\| \mathrm{IIS}$
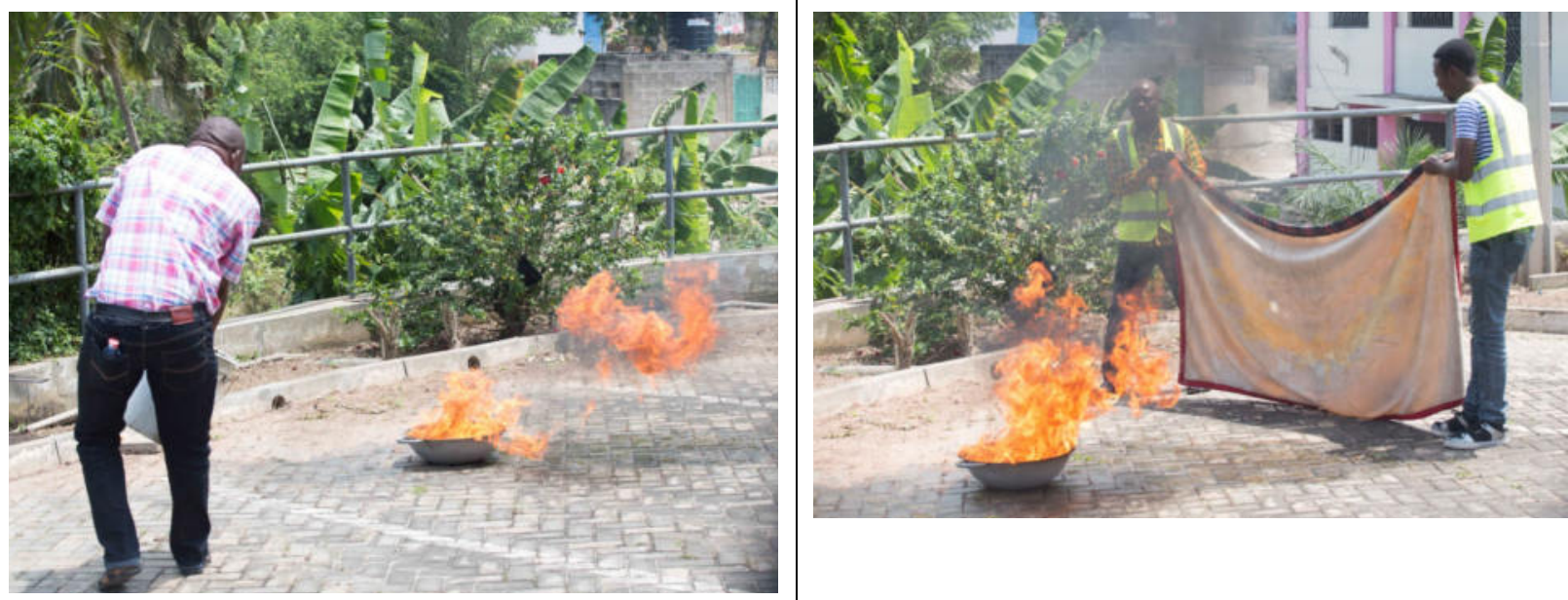

Fig. 5. Practical session. The use of water (left) and the use of wet blanket (right) to fight fire

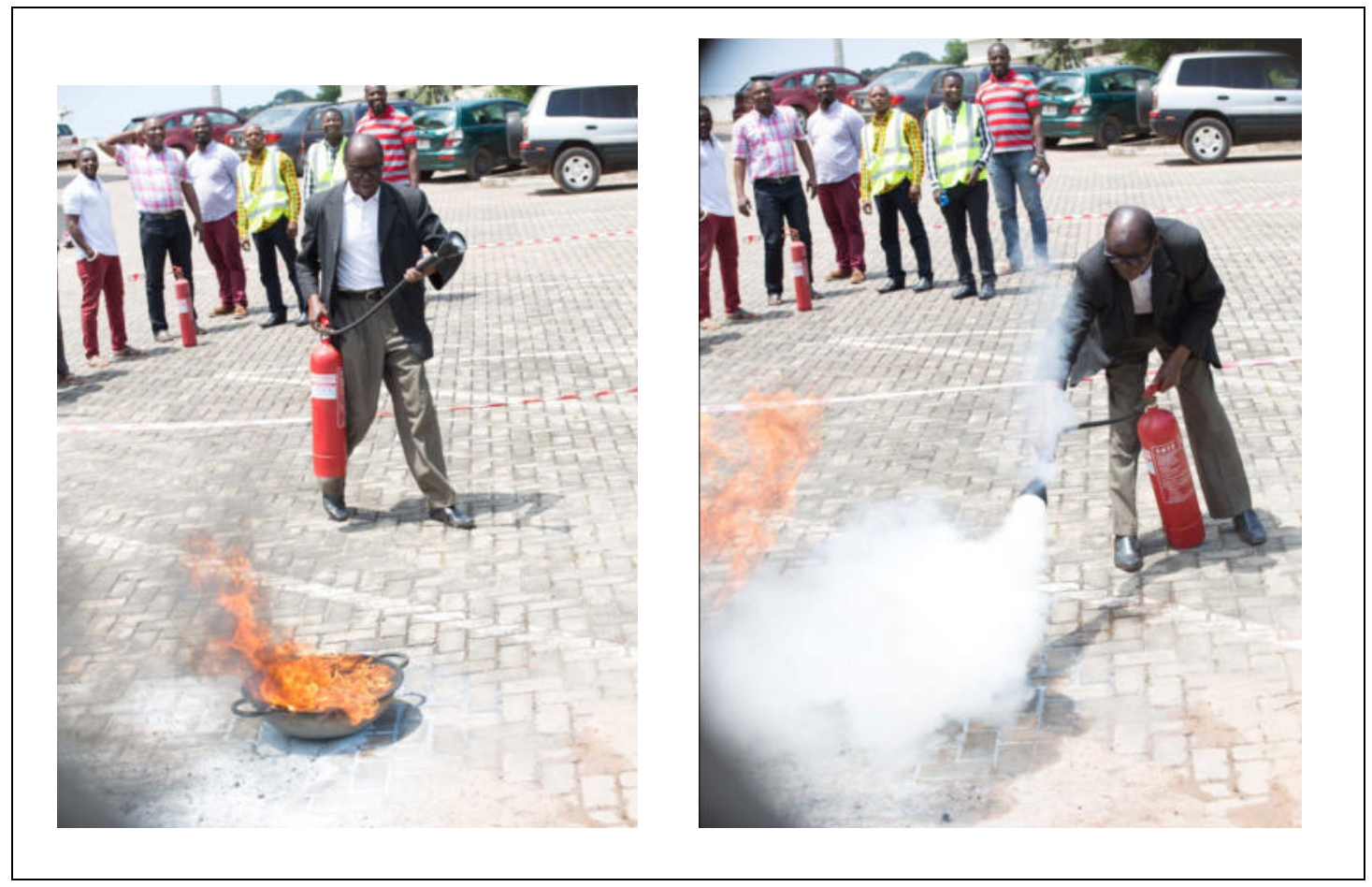

Fig.7. Demonstrating the use of Fire extinguishing to extinguish fire 

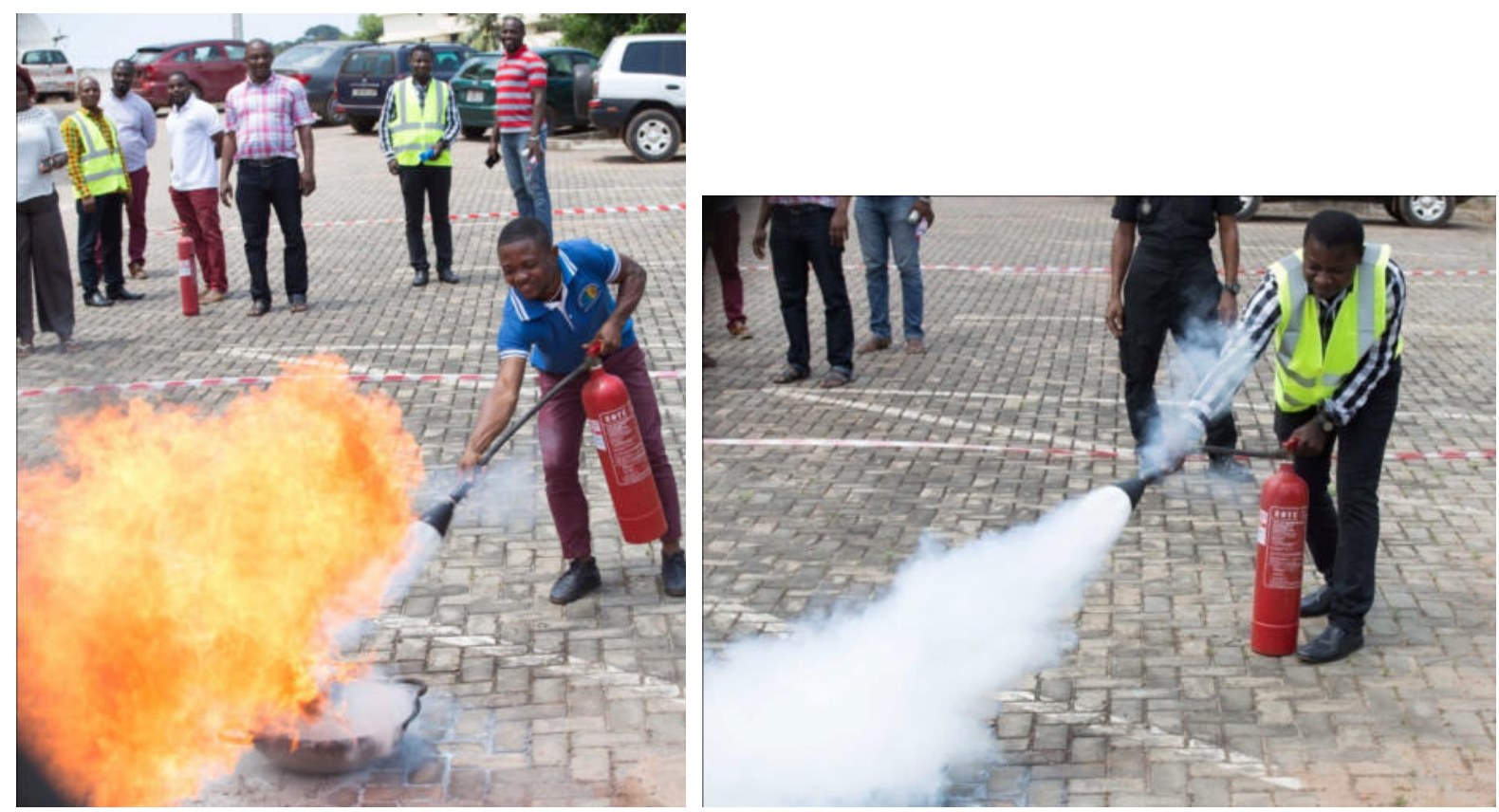

Fig 8. Staff and students practicing proper use of fire extinguisher to suppress fire 